\title{
Volunteering in medical oncology
}

\author{
Prashanth Hari Dass* \\ Medical Oncologist, Lakes DHB, Rotorua Hospital, New Zealand
}

\begin{abstract}
Volunteering is a humanitarian act that remains to be a choice freely made to every individual. Volunteering has numerous benefits to the individual and society. However, volunteering in the oncology community is uncommon due to multiple reasons. The rising disparities of cancer care and rising treatment costs is of concern. This article highlights the benefits of volunteering which needs to be promoted. Volunteering potentially raises the awareness of healthcare professionals, including oncologists to endeavour towards delivering accessible, affordable and equal global oncologic care in future.
\end{abstract}

\section{Introduction}

Volunteering among medical oncologists is poorly reported in the medical literature. The Compact Code of Good Practice on Volunteering defines volunteering as ".... an activity that involves spending time, unpaid, doing something that aims to benefit the environment or individuals or groups other than (or in addition to) close relatives". This humanitarian act is potentially inherent in every human being. Although the opportunity to volunteer is made available to each one of us, volunteering in itself can be hugely dependent on one's motive, availability and capability. Volunteering also remains to be a choice that needs to be freely made by every individual [1]. Volunteering among health care professionals and patients is well recognized and documented in the medical literature. However, literature on medical oncologist volunteering in areas of need is scarcely reported.

According to the World Health Organization, seventy percent of cancer related deaths occur in developing and under developed countries, with rising cancer incidences expected in the next two decades. The limited resources and poor access of patients to basic oncology services such as accurate and timely histological diagnoses, radiological staging and treatment is common. "Only 35\% of lowincome countries reported having pathology services generally available in the public sector. Cancer treatment services on the other hand are only available in $30 \%$ of low income countries compared to $90 \%$ of high income countries" [2]. The scenario described by Miklos Simon, Bhutan Program director where "two oncologists along with six oncology nurses handling the country's oncologic care" is highly commended, yet not uncommon even in this 21st century, in many developing nations [3]. The Honduras volunteering experience described by Chuang et al. [4] further echoes the plea of many developing countries requiring quality oncology services required to be put in place. With rising disparities in cancer care, volunteering in oncology may potentially bridge the gap and improve cancer services in less developed nations.

\section{Volunteering and Its Benefits}

Numerous benefits of volunteering have been documented. This includes but not limited to improving one's skill set, collaboration, curriculum vitae, gaining experience in global health, adaptability, and reviving one's passion and confidence in medicine $[5,6]$. Studies have reported that the reasons of volunteering given by most volunteers include a sense of responsibility, awareness and concern for the welfare of others [7,8]. Improved mental and physical well-being has also been reported [9]. A report by the All-Party Parliamentary Group on Global Health describes how United Kingdom (UK) health volunteers have made vast improvements in health overseas whilst at the same time benefiting UK; and far more potentially could be achieved through better organization, support and travel abroad [10]. An American national survey on 3,351 adults (Table 1) conducted by Harris interactive in 2013 via a mixed mode design, among people who volunteered in the last 12 months further illustrates the "self-reported" benefits of volunteering [11].

However, volunteering in oncology especially in a foreign country is not without its challenges. Academic pressures of an oncologist, language barriers in a foreign country, requirements for indemnity cover, medical registration, collaboration with local services, travel costs incurred to the volunteer, logistics, health and safety risks are only among the few of the many barriers to volunteer. In oncology, Health volunteer overseas are to be commended for their work for e.g. in Bhutan, Nepal and Vietnam. However, opportunities to

Table 1. Benefits derived from volunteering according to percentage (\%) of respondents

\begin{tabular}{|c|c|}
\hline $\begin{array}{l}\text { Percentage }(\%) \\
\text { of respondents }\end{array}$ & Benefits Derived from Volunteering \\
\hline $96 \%$ & Enriches their sense of purpose in life \\
\hline $95 \%$ & Helps them make their community a better place \\
\hline $94 \%$ & Improves their mood \\
\hline $81 \%$ & Strengthens relationships among colleagues \\
\hline $80 \%$ & Feel they have control over their health \\
\hline $78 \%$ & Lowers their stress levels \\
\hline $76 \%$ & Made them feel healthier \\
\hline $71 \%$ & $\begin{array}{l}\text { Provided them with job-related contacts and networking } \\
\text { opportunities. }\end{array}$ \\
\hline $49 \%$ & $\begin{array}{l}\text { Helped with their career; (of whom } 87 \% \text { agreed that it developed } \\
\text { their people skills and teamwork skills) }\end{array}$ \\
\hline $25 \%$ & Has helped them manage a chronic illness \\
\hline
\end{tabular}

*Correspondence to: Prashanth Hari Dass, Medical Oncologist, Lakes DHB, Rotorua Hospital, New Zealand, E-mail: prashanth.haridass@lakesdhb.govt.nz Received: July 12, 2018; Accepted: July 23, 2018; Published: July 25, 2018 
volunteer are only available to final year oncology fellows onwards, who are often required to be board certified and also paired to a boardcertified oncologist [12]. Proportion of oncologist who are involved in volunteering is unknown. However, a survey conducted on randomly selected academic orthopaedic surgeons; where $16 \%$ had completed the survey and $52 \%$ had volunteered abroad previously, the most common barriers described were scheduling, and family and social commitments (65\% and $66 \%$, respectively), followed by lack of specialty-specific opportunities (40\%) [13].

There are many volunteering non-profit organizations and charities that organize medical camps in low and middle-income countries to serve the needy [14]. However, many of these organizations or cooperatives facilitate a general medical platform rather than resource intensive oncologic platform which often involves high costs due to requirements for investigation, treatment, and long-term specialized follow-up [15-17]. Understanding one's role as a volunteer and joining an organization or group whose mission is consistent with one's values and objectives is also equally important when deciding to serve [18]. Despite its noble action, volunteering is also not without risk. Vandalism for example, has previously caused closure of a mobile clinic at a refugee camp [19]. Hence, oncologists should also ensure that they consider the liability implications prior to commencing voluntary work [20].

The key question now lies as to what can we as clinicians and scientists offer in return at a practical level to society? Efforts to train volunteers, forming volunteer corps and educational fellowships are stepping stones to reduce global cancer disparities [21-23]. Volunteering is not just for retirees. Mentors should motivate and support young trainee oncologist to start early, gain experience and serve less developed countries with appropriate supervision in addition to supporting their leave approval for noble work. Oncology trainees performing voluntary work should also have their service recognized by their training programmes [24]. Tertiary oncology specialist centres potentially could lend their expertise to assist and collaborate with cancer specialists or physicians with special interest in managing cancers in less developed nations. Utilizing telemedicine helps to also provide accessible, multi-disciplinary support and recommendations to developing nations [25].

On a personal note, being involved in medical camps in rural Fiji over the last decade has certainly helped me step out of my "comfort zone" and "broaden my vision". I have begun to appreciate the various challenges faced by developing nations to tackle global cancer care. Although our ability to diagnose cancers are limited in voluntary medical camps, from my experience it is not uncommon that patients often seek alternative treatments e.g. traditional healers prior to getting reviewed by doctors. The reasons for this are multifactorial and often due to poor education, lack of trust in the health system and limited resources. Diagnostic facilities and oncologic care in Fiji remain limited, with few available chemotherapy protocols, and very few fully qualified oncologists. To date, there are no radiotherapy facilities available in Fiji. Palliation and end of life-care is poorly managed.

Volunteering has reminded me to constantly evaluate the cost effectiveness of oncologic treatment. This awareness remains crucial. The way we design future treatment, route of administration and design of clinical trials needs to be tailored accordingly with global oncologic care and developing nations in mind. The ASCO annual meeting 2018 revealed multiple advances in cancer treatment. This would not have been possible without enrolment of patients into clinical trials. Prior studies have shown that between 3-33\% of oncology patients enrol into phase I trials for altruistic reasons [26]. However, vast majority of cancer
Table 2. Key principles for effective involvement in international development

\begin{tabular}{|c|c|}
\hline Key principles & Definition \\
\hline Ownership & Led and driven by the needs of developing countries \\
\hline Alignment & $\begin{array}{l}\text { In line with the host country's national, district and institution } \\
\text { level health plans }\end{array}$ \\
\hline Harmonization & Coordinated and "working as one" \\
\hline Evidence-based & Results are properly monitored, and projects evaluated \\
\hline Sustainable & Supported by a long-term commitment from all parties \\
\hline Mutually accountable & Responsibility for the project is shared by all partners \\
\hline
\end{tabular}

patients globally are neither able to access cancer trials nor access these cutting-edge treatments; yet alone dream of affording such treatment. If we as oncologist are contented with prescribing immunotherapy and targeted therapy to only a select group of patients, then the future of global cancer is grim and disparities will continue to widen.

\section{Conclusion}

In this light, the call for volunteering in medical oncology has come. Although volunteering may not be for every oncologist, sincere yearning to deliver quality, accessible and affordable oncologic care needs to be emphasized (Table 2) [14]. Regardless of caste, religion or creed, we as oncologist need to strive towards equality in global cancer care. Small initiatives like volunteerism may potentially provide rays of hope and spark awareness amongst us to give back to the society that we depend on.

\section{Acknowledgements}

I sincerely thank the volunteers of the Sathya Sai International Organizations of New Zealand and Fiji for their immense dedication and work in organizing and providing ongoing voluntary service work to the needy people of Fiji.

\section{Research support for the study}

$$
\text { Nil. }
$$

\section{References}

1. Paine AE, Hill M, Rochester C (2010) Revisiting the question: "what exactly is volunteering". Institute for Volunteering Research.

2. World Health Organization. Cancer (2017)

3. International Cancer Corps Provides Valuable First-Time Volunteer Experience (2013).

4. Chuang L, Sarchet V, Pyle D, Thomas M, Berry E, et al. (2015) Volunteering in Honduras: Results and Reflections. J Clin Oncol 33: 18.

5. Paine AE, McKay S, Moro D (2013) Does volunteering improve employability? Evidence from the British Household Panel Survey. Third Sector Research Centre Working Paper.

6. Keelan E (2015) So you want to be a Medical Volunteer. Ulster Med J 84: 220-221. [Crossref]

7. Nanni O, Serra P, Tison C, De Castro M, Ridolfi R, et al. (2006) Survey of the sociodemographic and motivational profile of volunteers in oncology. J Clin Oncol 24: 16011-16011.

8. Wojtacki J, Paczkowska A, Majkowicz M, Cieśnik A, Gurgul N, et al. (2016) Changes in demographic characteristics and motives for becoming a hospice/palliative care volunteer: Results of single institution 9 years educational program. J Clin Oncol 34: 3.

9. Yeung JWK, Zhang Z, Kim TY (2017) Volunteering and health. benefits in general adults: cumulative effects and forms. BMC Public Health 18: 1.

10. Crisp N (2007) Improving health at home and abroad: how overseas volunteering from the NHS benefits the UK and the world. A report on overseas volunteering and international partnerships; London: All-Party Parliamentary Group on Global Health.

11. Rubin K (2013) Doing good is good for you: 2013 health and volunteering study; Minnesota: United Health Group. 


\section{Health Volunteer Overseas}

13. Makhni MC, Miao D, Zurakowski D, Day CS (2014) Are academic orthopedic surgeons interested in global health?. Am J Orthop (Belle Mead NJ) 43: E37-42. [Crossref]

14. Department of Health (2010) NHS Framework for Involvement in International Development.

15. Feinmann J (2013) After the typhoon: how volunteer doctors are bringing medical care to those most in need. BMJ 347: $\mathrm{f7193.}$

16. Davies E (2013) Volunteer doctors start a clinic for the marginalized of New York city.

17. BM Kuehn (2013) Volunteer Corps Aims to Improve Training for Clinicians in Developing Countries. JAMA 309: 1982-1983.

18. J Kolkin (2014) A Physician's perspective on volunteering overseas... It's not all about sharing the latest technology. J Hand Ther 27: 152-157. [Crossref]

19. Hurley R (2016) Vandals force volunteer doctors to close clinic in Calais's refugee camp. BMJ 352: i182. [Crossref]
20. Kreimer S (2015) Volunteering: The benefits and risks for physicians. Medical Economics.

21. Fusco-Karmann C, Gangeri L, Tamburini M, Tinini G (1996) Italian Consensus on a Curriculum for Volunteer Training in Oncology. J Pain Symptom Manage 12: 39-46.

22. A Great IDEA: Celebrating 15 Years of the International Development and Education Award (2017).

23. ASCO Launches Volunteer Corps New Initiative Will Open Doors for Increased Opportunities for Member Participation (2017).

24. Academy of Medical Royal Colleges. Academy statement on volunteering: health professional volunteers and global health development; London: Academy of Medical Royal Colleges (2013)

25. Chuang L, Sarchet V, Pyle D, Thomas M, Berry E, et al. (2015) Volunteering in Honduras: Results and Reflections. J Clin Oncol 33: 18.

26. ECRI Evidence Report. Patients' Reasons for Participation in Clinical Trials and Effect of Trial Participation on Patient Outcomes (2002).

Copyright: $\left({ }^{\circ} 2018\right.$ Hari Dass P. This is an open-access article distributed under the terms of the Creative Commons Attribution License, which permits unrestricted use, distribution, and reproduction in any medium, provided the original author and source are credited. 